\title{
Papers
}

\section{Case-control study of the effect of mechanical trauma on the risk of herpes zoster}

\author{
S L Thomas, J G Wheeler, Andrew J Hall
}

Herpes zoster results from reactivation of latent varicella zoster virus infection. Risk of zoster increases with age and with depressed cell mediated immunity, but relatively little is known about other factors. ${ }^{1-3}$ Case reports and case series have indicated that mechanical trauma may be a risk factor. ${ }^{4}$ But these studies had no control group, and physical mishaps and surgical trauma are common in older people. We investigated whether trauma is associated with increased risk of zoster using a case-control design.

\section{Methods and results}

This investigation was part of a study based in general practice in London of the determinants of zoster in adults without underlying immunosuppression. Elsewhere, we describe recruitment and definitions of cases (patients with incident zoster) and controls (patients with no previous zoster, individually matched to cases by age, sex, and general practice) elsewhere. ${ }^{5}$ Participants gave informed consent.

We hypothesised that trauma increases the risk of zoster at the trauma site within one month of the trauma, as indicated by a previous case series. ${ }^{4}$ We asked participants about all physical trauma severe enough to cause bruising (without prompting as to the site of trauma) and about surgical procedures in the six months before interview. We compared occurrence of trauma among cases and their matched controls in the month before the case developed zoster, evaluating both trauma at the site of the case's rash and trauma occurring elsewhere. We used matched comparisons of the timing and site of trauma because the risk of trauma varies seasonally, and trauma occurs at certain body sites more often. We used multivariable conditional logistic regression to determine the independent effects of trauma on risk of zoster.

We got information on trauma for 243/244 cases (median age 57.2 years; range 16.5-91.2 years) and 483 matched controls. In the six months before interview, cases and controls had a similar frequency of trauma at body sites other than the site of the cases' zoster. But cases more often reported prior trauma at the site of their rash-this was associated with an eightfold increased risk of zoster as determined by multivariable analysis (table). Fourteen of the 22 participants who experienced trauma to the same site as subsequent zoster (mostly the trunk or head) did so in the month before the rash started (see table A on bmj.com). This recent trauma was associated with an adjusted 12-fold increased risk of zoster (table). Again, cases and controls had similar frequency of trauma to other body sites.

\section{Comment}

In this study, mechanical trauma was associated with a significantly increased risk of zoster the next month. The results indicate that trauma increases the risk of zoster at the trauma site, but not elsewhere. This suggests that traumatic stimulation of the nerve may trigger viral reactivation in the dorsal root ganglion of that nerve. The findings could be affected by recall bias-cases may have remembered more clearly that minor trauma occurred immediately before their zoster. Many of the 11 cases included in these analyses, however, reported memorable traumatic events-for example, undergoing cardioversion or being assaulted-and controls are unlikely to have forgotten such events.

Our sample size enabled us to show significant association with recent trauma, but only 14 participants had recent trauma at the site of the cases' zoster, resulting in wide 95\% confidence intervals. Most trauma experienced by cases was not followed by zoster at the trauma site, perhaps because zoster occurs most often within thoracic, lumbar, or trigeminal (ophthalmic) dermatomes, whereas physical injuries are more common elsewhere (such as the limbs). Traumatic stimulation of nerves in parts of the body predisposed to reactivation of varicella zoster virus may be relatively uncommon in older people, and so only a modest proportion of zoster cases are likely to result directly from trauma.

We thank all the patients who agreed to take part in the study; Albion Street Health Centre; Aylesbury Partnership; Belmont Hill Surgery; Brixton Hill Group Practice; Camberwell Green Surgery; Crown Dale Medical Centre; Grange Road Practice; Downham Way Surgery; Forest Hill Group Practice; Isidore Crown Health Centre; Jenner Health Centre; Lee Road Surgery; Mawbey Brough Health Centre; New Surgery, Clapham; Paxton Green Health Centre; Queens Road Partnership; Sternhall Lane Surgery; Sydenham Green Group Practice; Torridon Road Surgery; Judy Breuer for helpful discussions on the diagnosis of zoster and for analyses of the polymerase chain reactions.

Contributors: AJH conceived the study, and all authors contributed to the design. SLT ran the study, did the interviews, managed the data, and did the statistical analyses with input from AJH and JGW. All authors interpreted the findings and wrote the manuscript. SLT is guarantor.

Funding: SLT was funded initially by a research studentship from the Medical Research Council (UK) and then by the Research Foundation for Microbial Diseases, Osaka University.

Competing interests: None declared.

Ethical approval: Research ethics committees of Kings Healthcare, Guy's Hospital, St Thomas's Hospital, Lewisham Hospital Trust, and the London School of Hygiene and Tropical Medicine.

Table $A$ on bmj.com gives details of 14 people who had recent trauma at $\mathbf{P}+$ the site of subsequent rash in the case 
Effect of physical trauma on the risk of zoster

\begin{tabular}{|c|c|c|c|c|}
\hline Physical trauma & No of cases $(\%)$ & No of controls $(\%)$ & Univariable odds ratio ( $95 \% \mathrm{Cl}$; $\mathrm{P}$ value) & Adjusted odds ratio"(95\% Cl; P value) \\
\hline \multicolumn{5}{|l|}{ Past six months } \\
\hline \multicolumn{5}{|l|}{ At any site: } \\
\hline No & $182(74.9)$ & $370(76.6)$ & 1.00 & 1.00 \\
\hline Yes & $61(25.1)$ & $113(23.4)$ & 1.10 (0.77 to $1.58 ; P=0.598)$ & $1.08(0.72$ to $1.61 ; P=0.716)$ \\
\hline \multicolumn{5}{|c|}{ At different site to rash: } \\
\hline No & $198(81.5)$ & $373(77.2)$ & 1.00 & 1.00 \\
\hline Yes & $45(18.5)$ & $110(22.8)$ & 0.77 (0.52 to $1.14 ; P=0.182)$ & 0.75 (0.49 to $1.16 ; P=0.191)$ \\
\hline \multicolumn{5}{|c|}{ At same site as rash: } \\
\hline No & $226(93)$ & $478(99.0)$ & 1.00 & 1.00 \\
\hline Yes & $17 \quad(7.0)$ & $5(1.0)$ & 10.38 (3.02 to 35.62; $\mathrm{P}<0.0001)$ & 8.02 (2.24 to $28.69 ; P=0.0002$ ) \\
\hline \multicolumn{5}{|c|}{ Month before rash onset† } \\
\hline \multicolumn{5}{|l|}{ At any site: } \\
\hline No & $217(89.7)$ & $457(94.6)$ & 1.00 & 1.00 \\
\hline Yes & $26(10.7)$ & $26 \quad(5.4)$ & 2.28 (1.25 to $4.18 ; P=0.007)$ & 2.61 (1.31 to 5.19; $P=0.006)$ \\
\hline \multicolumn{5}{|c|}{ At different site to rash: } \\
\hline No & $228(93.8)$ & $459(95.0)$ & 1.00 & 1.00 \\
\hline Yes & $15 \quad(6.2)$ & $24 \quad(5.0)$ & 1.28 (0.65 to $2.55 ; P=0.478$ ) & 1.59 (0.74 to $3.45 ; P=0.242$ ) \\
\hline \multicolumn{5}{|c|}{ At same site as rash: } \\
\hline No & $232(95.5)$ & $480(99.4)$ & 1.00 & 1.00 \\
\hline Yes & $11 \quad(4.5)$ & $3(0.6)$ & 19.08 (2.44 to $149.10 ; P=0.0001)$ & 12.07 (1.49 to $97.63 ; P=0.002)$ \\
\hline
\end{tabular}

${ }^{*}$ Adjusted for social and occupational child contacts, varicella contacts, major stress events in the two months before rash onset, and current illness.

†Trauma occurring to cases or to their matched controls in the month before the case developed rash.

1 Arvin AM. Cell-mediated immunity to varicella-zoster virus. J Infect Dis 1992;166(suppl):S35-41.

2 Burke BL, Steele RW, Beard OW, Wood JS, Cain TD, Marmer DJ. Immune responses to varicella-zoster in the aged. Arch Intern Med 1982;142:291-3.

3 Morens DM, Bregman DJ, West CM, Greene MH, Mazur MH, Dolin R, et al. An outbreak of varicella-zoster virus infection among cancer patients. Ann Intern Med 1980;93:414-9

4 Juel-Jensen BE. The natural history of shingles: events associated with reactivation of varicella-zoster virus. J R Coll Gen Pract 1970;20:323-7.

5 Thomas SL, Wheeler JG, Hall AJ. Contacts with varicella or with children and protection against herpes zoster in adults: a case-control study. Lancet 2002;360:678-82.

(Accepted 29 October 2003) doi $10.1136 /$ bmj.37991.511829.F7

Infectious Disease Epidemiology Unit, London School of Hygiene and Tropical Medicine, London WC1E 7HT

S L Thomas clinical lecturer

Andrew J Hall professor

Department of Public Health and Primary Care, Institute of Public Health,

Cambridge CB2 2SR

$\mathrm{J} \mathrm{G}$ Wheeler lecturer

Correspondence to: S L Thomas sara.thomas@lshtm.ac.uk 